\title{
A User's Guide to Misanalyzing Planned Experiments
}

\author{
Charles E. Gates \\ Department of Statistics, Texas A\&M University, College Station, TX 77843
}

I have more than 30 years of experience in consulting with research workers on the design, analysis, and interpretation of their experiments. Much of this experience has been with agricultural and biological research workers, but I dare say the abuses and misuses I have found are analogous to any field. It has occurred to me over time that the same errors are being repeated. But what is even more than potentially frightening is the recent availability of very powerful computer software packages on microcomputers, giving people more computing power than was available in mainframe computers only a few short years ago. The wide-spread availability of these powerful microcomputers with very general and equally powerful software packages has its analog in many other areas of life; there is enormous potential for good and for bad. If a user, however dedicated or conscientious, decides to "do his thing" with a set of data, when the researcher is in reality out in "left field," who is going to stop the user from illogical, ill-advised, and incorrect analyses? The researcher may have expert statistical advice available but cannot be bothered to wait a day or two for an appointment to check to see if the model under consideration is appropriate for the design. Or even worse, suppose that no professional statistical advisor is even available within our conscientious researcher's organization. I cannot verify it personally, but I have heard the apocryphal story that some research administrators think that statisticians are now passé with the advent of these all-powerful desk-top computers! Although I have had no personal experience, I would judge that some of the "expert system" computer programs in experimental design would fare no better with naive users.

It is my contention that the only solution is education, education, and more education of the end-user. I am not talking about the researcher who uses the identical experimental design year after year and who thoroughly understands the advantages and disadvantages of the design and is intimately familiar with its correct layout in the field, oven, or greenhouse bench, as the case may be, and

\footnotetext{
Received for publication 15 Oct. 1990. I am deeply indebted to many individuals for encouraging the writing of and for critiquing this version of the manuscript, but especially to Mel Carter, Ron Hocking, Mort Kothmann, and Scott Urquhart. All remaining misinterpretations are my own. The cost of publishing this paper was defrayed in part by the payment of page charges. Under postal regulations, this paper therefore must be hereby marked advertisement solely to indicate this fact.
}

last, but by no means least. with its correct analysis and interpretation. There are actually researchers who for good and sufficient reasons (including legal ones) employ the same designs repeatedly. Even so, those who can should re-examine the situation every 5 or 10 years. I am referring to the researchers who perhaps use a novel design (to them), or, heaven forbid, have been incorrectly analyzing a given design for many years. It cannot be overemphasized that statistical knowledge is all important in providing correct models.

In the next section, I enumerate some of the common statistical errors that I see, while the last section enumerates some basic principles of experimental design. Tests of significance are emphasized throughout, but the principles are the same for ascertaining unbiased standard errors, confidence intervals, etc.

\section{COMMON ABUSES AND MISUSES OF PLANNED EXPERIMENTS}

This list of common abuses and misuses is in no particular order, although some of the more common and serious errors are near the beginning of the list.

1. Incorrectly analyzing split-plot designs. This is a very frequent occurrence; far too frequent to be a chance event. I think part of the problem is the pernicious terminology (even by well-known statisticians) of "factorial designs." The phrase "factorial designs" is at best a misleading, if not incorrect, phrase. The reason is that the phrase "factorial designs" tells us nothing about the design per se of the experiment. The design of an experiment has to do with blocking factors or absence thereof. A more precise terminology is "factorial experiment," which merely says that factorial arrangement of treatments is present; the design could be completely randomized (CRD), randomized (complete) block (RBD), split-plot (SPD), etc. Of course, if we have a SPD experiment, we know there must be at least two treatment factors.

The usual incorrect analysis of a SPD experiment is its analysis as if the design had been a two-factor factorial in a RBD experiment. The net effect is that the two customary error terms for the SPD, in such a case, are pooled and used to test all treatment effects. The difficulty with that analysis is that the pooled error typically will be badly biased downward and will have far too many degrees of freedom (df) for testing whole-plot treatments. Thus, whole-plot treatments will typically show significance, possibly at the 0.0001 level, when, if tested by a correct error term, they may not even show significance. The pooled error term for testing the split-plot treatments and the interaction typically will be somewhat too large, but this will be partially compensated for by the additional df available for the test. These remarks are illustrated with a typical example in Table 1. This example, actually designed and run as a SPD (Fig. 1), consisted of the irrigation treatments and fertility rates for cotton grown in the high plains of Texas. Of necessity, large plots are needed for the irrigation treatments employed; economically, it is infeasible to have many replications of the irrigation treatments (two in our example), but the four fertility treatments can be applied readily in much smaller areas.

It is also obvious that, even aside from tests of significance, the SE for whole-plot treatments computed from the incorrect, pooled error will be badly biased.

For details of the correct analysis of SPDs, refer to any good statistical methods reference book, such as Sokal and Rohlf (1981).

A generalization of the "incorrectly analyzed split-plot error" is the "use of an incorrect error term" from misapplying or failing to understand the concept of random and fixed effects and mean square expectations (see the fourth "basic principle" below).

2. Failure to recognize the distinction between nested and crossed (factorial) factors. Researchers may be unaware that, if they understand the distinction between CRD and $\mathrm{RBD}$, they have within their grasp an easy explanation of the distinction between nested and crossed effects. A typical incorrect assignment exists when a researcher places in the model a term for samples, when there is no rationale or justification for matching the first, or indeed any, samples from each plot. This error may not be nearly as serious as the previous error. The researcher will merely have an additional term in the model to explain, where significance or lack thereof will not seriously impair the overall interpreta-

Table 1. A split-plot design incorrectly analyzed as a two-factor factorial in a randomized-block design and analyzed correctly.

\begin{tabular}{lrrlr}
\hline \multicolumn{2}{c}{ Incorrect } & & & \multicolumn{2}{c}{ Correct } \\
\cline { 5 - 5 } S.V.z & df & & S.V. & df \\
\hline Total & 15 & & Total & 15 \\
Reps & 1 & & Reps & 1 \\
Irrigation & 1 & & Irrigation & 1 \\
Fertility & 3 & & Error (a) & 1 \\
IF & 3 & & Fertility & 3 \\
Error & 7 & & IF & 3 \\
& & Error (b) & 6 \\
\hline
\end{tabular}

${ }^{\mathrm{z} S . V}$., source of variation. 
tion. Of course, experimenters could and sometimes do get carried away and fit a threefactor factorial, i.e., interactions of his supposed "sample" factor with various blocking and treatment factors, which leads to certain difficulties in interpretation. Table 2 shows a typical RBD with sampling, the correct analysis, and the two incorrect models alluded to.

3. Substitution of sampling error for experimental error, or arbitrarily combining these two errors. Although this abuse of statistics was pointed out by George Snedecor many decades ago, it still occurs with monotonous frequency. How many times, for example, have I argued with poultry scientists that with 12 pens of broilers, four penfed dietary treatments, three blocks (pen levels), and 10 broilers per pen, the correct error term for testing the effect of diet on body weight is the experimental error with exactly 6 , not sampling error with 108 , df! How many hundreds (thousands?) of papers have survived the refereeing process and been published in exactly this situation? A simple example is provided in Table 3.

4. Designing experiments with unreplicated treatment factors. This is one of the most common errors that even some of our own statistics majors often fail to recognize. They simply fail to recognize that it is quite possible and all too common to have certain treatment factors replicated and others unreplicated, even within the same experiment. Common examples of this occur with growth chambers, plot treatments involving aerial spraying, and forage pasture experiments with large animals. Using the former example, graduate student Ms. XYZ is given the use of two growth chambers to run an experiment in conjunction with her Master's program. There are two temperatures to be investigated for growing the ornamental $E u$ onymus atropurpureus, four cultivars, three fertility treatments, and two plants per growth chamber per species per fertility level. Thus, 24 plants are randomly assigned within each of the two growth chambers. The two temperatures are assigned literally at random to the two growth chambers. Obviously, temperatures cannot be tested, as that factor was never replicated. Certainly, the model can and should be written to include a term for "temperature," but there is no valid error term for that effect, despite what the software labels as "error."

Hammer and Urquhart (1979) discuss in depth the issues involved and the correct analyses of controlled environmental studies. Another view of the problem of lack of replication in planned experiments is afforded by Hurlbert (1984). This paper has been quoted widely in the ecological press; basically, Hurlbert notes that many researchers incorrectly use samples to test nonreplicated treatments in field experiments.

There is an "out," however, from the lack of replication, provided that the experiment has three, or preferably more, levels of the unreplicated factor (providing it is a quantitative factor). Suppose that in the above experiment, there were three growth cham-

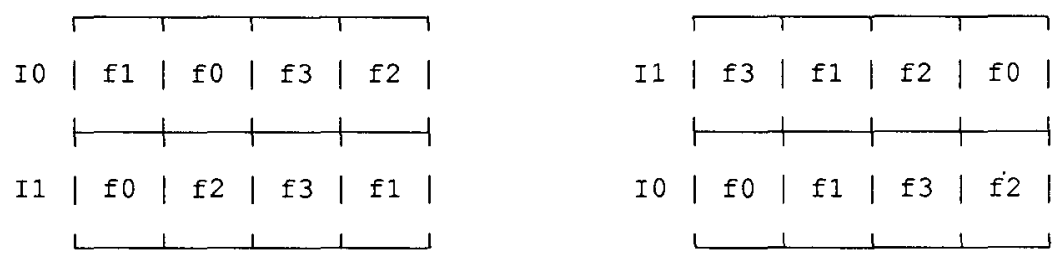

Block I

Block II

Fig. 1. Irrigation (I) and fertility rates (f) in a split-plot arrangement on cotton.

Table 2. Randomized-block design with sampling: some incorrect and correct analyses thereof.

\begin{tabular}{|c|c|c|c|c|c|}
\hline \multicolumn{2}{|c|}{ Incorrect no. 1} & \multicolumn{2}{|c|}{ Incorrect no. 2} & \multicolumn{2}{|c|}{ Correct } \\
\hline S.V. ${ }^{2}$ & df & S.V.z & df & S.V.z & df \\
\hline Total & rst-1 & Total & rst-1 & Total & rst-1 \\
\hline Blocks (B) & $\mathrm{r}-1$ & Blocks & $\mathrm{r}-1$ & Blocks & $\mathrm{r}-1$ \\
\hline Trts. (T) & $t-1$ & Trts. & $t-1$ & Trts. & $t-1$ \\
\hline BT & $(\mathrm{r}-1)(\mathrm{t}-1)$ & BT & $(\mathrm{r}-1)(\mathrm{t}-1)$ & Expt. error & $(\mathrm{r}-1)(\mathrm{t}-1)$ \\
\hline Samples (S) & s-1 & Samples & s-1 & $\begin{array}{l}\text { Sampling } \\
\text { Error }\end{array}$ & $\operatorname{rt}(s-1)$ \\
\hline Residual & $(\mathrm{s}-1)(\mathrm{rt}-1)$ & $\begin{array}{l}\text { SB } \\
\text { ST } \\
\text { SBT }\end{array}$ & $\begin{array}{c}(s-1)(r-1) \\
(s-1)(t-1) \\
(s-1)(r-1)(t-1)\end{array}$ & & \\
\hline
\end{tabular}

${ }_{\text {SS.V., source of variation. }}$

Table 3. Randomized (complete) block design with mean square expectations (random-block and fixed-treatment effects). ${ }^{\mathrm{x}}$

\begin{tabular}{|c|c|c|c|}
\hline S.V. & $\mathrm{df}$ & MS & $\mathrm{E}(\mathrm{MS})$ \\
\hline Total & rst-1 & & \\
\hline Blocks & $\mathrm{I}-1$ & $\mathrm{M}_{\mathrm{b}}$ & -.. \\
\hline Trts. & $\mathrm{t}-1$ & $\mathrm{M}_{\mathrm{t}}$ & $\sigma_{\mathrm{s}}^{2}+s \sigma_{\mathrm{tb}}^{2}+\mathrm{rs} \Sigma \tau_{j}^{2} /(\mathrm{t}-1)$ \\
\hline Expt. error & $(\mathrm{r}-1)(\mathrm{t}-1)$ & $\mathrm{M}_{\mathrm{e}}$ & $\sigma_{\mathrm{s}}^{2}+s \sigma_{\mathrm{tb}}^{2}$ \\
\hline Sampling error & $\mathrm{rt}(\mathrm{s}-1)$ & $\mathrm{M}_{\mathrm{s}}$ & $\sigma_{s}^{2}$ \\
\hline
\end{tabular}



hers available for testing three temperature levels. I do not think anyone could quibble with use of lack-of-fit, deviations from the fitted model, in order to test treatments. In this case, it is perfectly proper to use deviations from linear temperature effects to test linear treatment effects. The use of lack-offit to test the fitted model is a conservative test because if the model is inadequate, it will be biased upward. The test will be of extremely low power, due to the low df involved and possibly also due to the bias mentioned. But the aerial sprayers, large animal, and growth chamber experimenters can have unreplicated experiments, provided there are three or more levels of the aforementioned quantitative factor.

5. Overuse of multiple comparison procedures. Apparently, we as a profession have oversold multiple comparison procedures. All too often "Duncan's" is applied to a set of data, irrespective of whether the treatment factors are quantitative or qualitative or some combination thereof. This is a particularly pernicious error, especially if the "treatments" happen to be comprised of a factorial arrangement of factors. Little's (1978) tonguein-cheek article, "If Galileo Published in HortScience," presents a $6 \times 2$ factorial, with six time intervals in which two different "fruits" were dropped, puffballs and apples. Then, of course, Duncan's multiple range test is misapplied to the 12 treatment com- binations. The results of the incorrect analysis are summarized in Table 4 . The correct analysis is clearly to analyze the data as a 2 $\times 6$ factorial, presumably in a CRD. If the interaction is nonsignificant, then the two treatment factors can be interpreted independently; if the interaction is significant, then the two "fruits" can be compared for each distance or, alternatively, the distances evaluated with linear, quadratic, etc. for each "fruit." There are many relevant articles in the literature on the misuses and role of multiple comparison procedures. In addition to Little's paper, see the series of papers by Jones (1984), Perry (1986), and Jones and Matloff (1986).

6. The incorrect analysis of factorial experiments consisting of a qualitative factor (with $b$ levels) and a quantitative factor with $a$ levels, including the zero level. I see several of these a year; sometimes the researchers are cognizant that they do not have complete $a \times b$ factorials and sometimes they are not. These designs are very common in spraying treatments, where the quantitative factor is the amount of the qualitative factor, spray material. Other examples are sources of $\mathrm{N}$ vs. rates and storage experiments with storage temperature vs. length of storage, including 0 (this latter case is actually a factorial with two quantitative factors, so the terminology needs updating). The basic difficulty here, as alluded to above, is 
Table 4. Distance of fall in various lengths of time for puffballs and apples.

\begin{tabular}{llc}
\hline \hline $\begin{array}{c}\text { Time } \\
(\mathrm{sec})\end{array}$ & $\begin{array}{l}\text { Kind of } \\
\text { "fruit" }\end{array}$ & $\begin{array}{c}\text { Distance of } \\
\text { fall }(\mathrm{m})^{\mathrm{z}}\end{array}$ \\
\hline 0.5 & Puffball & $0.6 \mathrm{a}$ \\
0.5 & Apple & $1.3 \mathrm{a}$ \\
1.0 & Puffball & $3.1 \mathrm{ab}$ \\
1.0 & Apple & $4.7 \mathrm{ab}$ \\
1.5 & Puffball & $8.2 \mathrm{abc}$ \\
1.5 & Apple & $10.9 \mathrm{bcd}$ \\
2.0 & Puffball & $15.7 \mathrm{~cd}$ \\
2.0 & Apple & $19.1 \mathrm{de}$ \\
2.5 & Puffball & $24.7 \mathrm{ef}$ \\
2.5 & Apple & $30.1 \mathrm{fg}$ \\
3.0 & Puffball & $36.4 \mathrm{gh}$ \\
3.0 & Apple & $43.2 \mathrm{~h}$ \\
\hline
\end{tabular}

${ }^{2}$ Mean separation by Duncan's multiple range test, $P=0.05$. From Little (1978), with permission.

that there are only $\{b(a-1)+1\}$ unique treatments. A correct analysis of such experiments was communicated by Addelman (1974) many years ago (see Hocking, 1985, for a modern, linear models approach). A hypothetical example of a $\mathrm{N}$ source vs. rate experiment is shown in Table 5 and the correct analysis in Table 6. For the data set shown, there are no important differences in interpretation between the two analyses. However, the data set could be modified readily to cause an entirely erroneous interpretation when using the incorrect analysis. For computational details, see Table 7. Parenthetically, while the individual steps can be performed readily on many commercial software packages, it does not appear possible to do the complete analysis in one pass, using standard procedures.

7. Failure to use correct error terms in regression analyses of planned experiments. Consider a RBD with sampling. Suppose that we have an aerial spraying experiment for honey mesquite on rangeland in West Texas. We will suppose that this is an early experiment and we are using herbicide TUV at six spaced levels of the chemical, including zero. Naturally enough, the experimenter is interested in determining the response of the increasing levels of TUV and fits the linear and quadratic effects with the wrong model shown in the left half of Table 8 and shows the correct analysis in the right half. In fitting regression models using planned experiments, the experimenter must use the standard $\mathrm{RBD}$ error term as the only valid error term whether the researcher is "doing regression" or is "doing ANOVA."

8. Failure to analyze the experiment as designed. This is admittedly a generalization of many of the "sins" enumerated above. An example came to my attention very recently. The researcher was interested in studying the interplay of irrigation and cultivars on cotton planted in fields on the Brazos river bottoms in Brazos County, Texas. Unfortunately, the experiment was designed as two adjacent RBDs with the designs and the irrigation treatments totally confounded. Thus, any test of significance on "irrigation" may be as much for inherent differences in the two areas as it is for the irrigation effects (this is also an example of no repli-

Table 5. Kilotons of dry matter produced per hectare with various sources of nitrogenous fertilizers and varying rates of $\mathrm{N}$.

\begin{tabular}{|c|c|c|c|c|c|c|c|c|}
\hline \multirow[b]{3}{*}{ Source } & \multicolumn{8}{|c|}{ Rate } \\
\hline & \multicolumn{4}{|c|}{ Rep. I } & \multicolumn{4}{|c|}{ Rep. II } \\
\hline & 0 & 50 & 100 & 500 & 0 & 50 & 100 & 500 \\
\hline$\left(\mathrm{NH}_{4}\right)_{2} \mathrm{SO}_{4}$ & 9 & 15 & 20 & 25 & 16 & 20 & 25 & 30 \\
\hline $\mathrm{KNO}_{3}$ & 11 & 16 & 21 & 26 & 14 & 19 & 24 & 29 \\
\hline $\mathrm{NH}_{4} \mathrm{NO}_{3}$ & 13 & 17 & 27 & 37 & 12 & 25 & 35 & 45 \\
\hline
\end{tabular}

Table 6. Incorrect and correct ANOVA for the data in Table 5.

\begin{tabular}{|c|c|c|c|c|c|}
\hline \multicolumn{3}{|c|}{ Incorrect $^{z}$} & \multicolumn{3}{|c|}{ Correct $^{z}$} \\
\hline S.V. & $\mathrm{df}$ & MS & S.V. & $\mathrm{df}$ & MS \\
\hline Total & 23 & $-\cdots$ & Total & 23 & $\ldots$ \\
\hline Blocks & 1 & 135.4 & Blocks & 1 & 135.4 \\
\hline Treatments & 11 & $147.1^{* *}$ & Treatments & 9 & $181.1^{* *}$ \\
\hline Source (S) & 2 & $108.4^{* *}$ & Source & 2 & $144.5^{* *}$ \\
\hline Level (L) & 3 & $424.8^{* *}$ & Level & 3 & $424.8^{* *}$ \\
\hline SL & 6 & $23.2^{* *}$ & SL & 4 & $16.7^{* *}$ \\
\hline Error & 11 & 3.74 & Error $\dagger$ & 13 & 3.16 \\
\hline
\end{tabular}

${ }^{\mathrm{z} S}$.V., source of variation; MS, mean squares.

$\dagger$ This error is actually comprised of the nominal blocks * trt interaction with 9 df plus the variability of the check treatments (with three "sources" at the zero level) within replications with $4 \mathrm{df}$. **Significant at $\alpha=0.01$.

Table 7. Computational details for analyzing a two-factor factorial with one qualitative and one quantitative factor with a zero level in randomized-block design [adapted from Addelman (1974)].

\begin{tabular}{|c|c|c|}
\hline Source & df & Sums of squares ${ }^{2}$ \\
\hline Blocks & $\mathrm{r}-1$ & $\mathrm{~S}_{\mathrm{r}}=\sum_{\mathrm{k}=1}^{\mathrm{r}} \mathrm{Y}_{. \mathrm{k}}^{2} / \mathrm{ab}-\mathrm{Y}_{\ldots}^{2} / \mathrm{abr}$ \\
\hline A (Quant. factor) & $a-1$ & $\mathrm{~S}_{\mathrm{a}}=\sum_{\mathrm{i}=1}^{\mathrm{a}} \mathrm{Y}_{\mathrm{i} .}^{2} / \mathrm{br}-\mathrm{Y}_{\ldots}^{2} / \mathrm{abr}$ \\
\hline B (Qual. factor) & b-1 & $\mathrm{S}_{\mathrm{b}}=\sum_{\mathrm{j}=1}^{\mathrm{b}} \mathrm{Y}_{\mathrm{j}}^{2} /(\mathrm{a}-1) \mathrm{r}-\mathrm{Y}_{. .}^{2} /(\mathrm{a}-1) \mathrm{br}$ \\
\hline$A \times B$ & $(a-2)(b-1)$ & $\mathrm{S}_{\mathrm{ab}}=\sum_{\mathrm{i}=2}^{\mathrm{a}} \sum_{\mathrm{j}=1}^{\mathrm{b}} \mathrm{Y}_{\mathrm{ij}}^{2} / \mathrm{r}-\mathrm{S}_{\mathrm{b}}-\sum_{\mathrm{i}=2}^{\mathrm{a}} \mathrm{Y}_{\mathrm{i} .}^{2} / \mathrm{br}$ \\
\hline $\begin{array}{l}\text { Experimental error } \\
\text { Total }\end{array}$ & $\begin{array}{l}\text { Subtraction } \\
\quad \text { abr }-1\end{array}$ & $\begin{array}{c}\mathrm{S}_{\mathrm{c}}=\mathrm{S}_{\mathrm{t}}-\mathrm{S}_{\mathrm{r}}-\mathrm{S}_{\mathrm{a}}-\mathrm{S}_{\mathrm{b}}-\mathrm{S}_{\mathrm{ab}} \\
\mathrm{S}_{\mathrm{t}}=\sum_{\mathrm{ijk}}^{\mathrm{abr}} \mathrm{Y}_{\mathrm{ijk}}^{2}-\mathrm{Y}^{2} / \mathrm{abr}\end{array}$ \\
\hline
\end{tabular}

${ }^{2}$ Where $Y_{\mathrm{ijk}}=\mu+\rho_{\mathrm{k}}+\alpha_{\mathrm{i}}+\beta_{\mathrm{j}}+(\alpha \beta)_{\mathrm{ij}}+\epsilon_{\mathrm{ijk} .} . \mathrm{Y}_{.{ }_{\mathrm{k}} \mathrm{k}}=$ block totals; $\mathrm{Y}_{\mathrm{i} . .}=$ Factor A totals; $\mathrm{Y}_{_{\textrm{j} *}}$

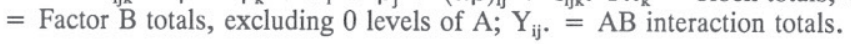

Table 8. Incorrect and correct "regression analysis" of a randomized-block design with sampling.

\begin{tabular}{|c|c|c|c|}
\hline \multicolumn{2}{|c|}{ Incorrect } & \multicolumn{2}{|c|}{ Correct } \\
\hline S.V. & $\mathrm{df}$ & S.V. & df \\
\hline Total & rst-1 & Total & rst-1 \\
\hline Linear & 1 & Blocks & $\mathrm{r}-1$ \\
\hline Quadratic & 1 & Trts & $t-1$ \\
\hline \multirow[t]{5}{*}{ Residual } & rst-3 & Linear & 1 \\
\hline & & Quadratic & 1 \\
\hline & & Deviations & $t-3$ \\
\hline & & Expt. error & $(\mathrm{t}-1)(\mathrm{r}-1)$ \\
\hline & & Sampling error & $\operatorname{tr}(s-1)$ \\
\hline
\end{tabular}

cation of irrigation treatments).

9. The belief that a set of raw data has to be normally distributed. This is, of course, only true with a random-effects model. It is the residuals that must be normally distributed (for validity of the resulting $\mathrm{F}$ tests) in all mixed and fixed models. A corollary is the wide-spread belief that percentage data must always be transformed, although here the emphasis may be as much, if not more, on the heteroscedasticity as the normality violation. Nowhere in the underlying ANOVA assumptions is it stated that "percentage data must be transformed." Note there are basically two types of percentage data: the "customary" ones calculated from ratios of counts ("successes" vs. "failures") and those from ratios of quantitative variables (e.g., percent moisture). In the former case, one should consider a type of categorical analysis.

\section{BASIC PRINCIPLES OF EXPERIMENTAL DESIGN}

1. Fisher's (1951) Principles of Experimental Design; randomization, replication, and control. These principles are so basic that I will spend little space in explanation (and in any event, Fisher did it better). Assignments of treatments to the experimental units must contain some element of random. ness to achieve a correct error term. Replication of treatments in different experimental units is essential to separate the effects of the treatments from the inherent differences in experimental units. By control, Fisher was referring to care in treating experimental units as much alike as possible, so as to reduce experimental error.

2. The researcher must know what the experimental unit is. This may seem rather ob. 
vious, and should be to anyone who has ever designed a SPD, where there are two different-sized experimental units, by definition. An experimental unit is the basic unit to which a given treatment is applied. In the irrigation experiment referred to (error no. 1, above), there are two experimental units, the large areas, conventionally called whole plots, to which the irrigation treatments are applied, and the smaller plots, conventionally called split plots, to which the fertility treatments are applied. An exceedingly general principle of experimental design states that for the "usual" models with treatment factors fixed and blocking factors random, treatments will be tested by residual variability of experimental units of the same level. Thus, "wholeplot treatments" are tested usually by error (a) in the SPD, rather than error (b). In error no. 3 above, the experimental unit in a penfed dietary experiment is clearly the whole pen, not the individual broilers. For the basic principles enumerated in items $2-8$, see Lentner and Bishop (1986).

3 . The concept of random and fixed effects must be understood. The only exception I would permit would be by the researcher who employs the same design year after year, for good and sufficient reasons. However, even there the researcher should periodically reanalyze his plot technique with a fresh view.

4. The user must understand mean square expectations. The only exception I would permit would be by the rare experimenter who only used CRDs and RBDs, without subsampling. The reason that the mean square expectation concept is so important in experimental design is that such knowledge is absolutely required in order to recognize what the correct "error" term is, except for the most trivial cases.

5. The researcher must recognize the basic designs: CRDs, RBDs, LSDs, SPDs and incomplete block designs (ICBDs). If the endusers of these designs are familiar with even just this basic set, it is less likely that they will analyze the design incorrectly.

6. The design of an experiment is determined solely by the blocking factors, or lack thereof. "A factorial experiment," while a valid phrase, tells us essentially nothing about the experiment's design. One can choose treatments, e.g., in the form of a factorial in a CRD, RBD, SPD, or LSD.

7. Regression and ANOVA are not unrelated statistical techniques but are closely related. It is certainly possible to complete an ANOVA using regression techniques and, undoubtedly, also the converse (see error no. 7 above). The corollary to this principle is that the correct error term must be used in "regression analyses" of planned experiments.

8. An experiment must be analyzed as designed, at least initially. This means that it is completely unethical to analyze a SPD experiment as a two-factor factorial, or to analyze a RBD with sampling as if it were an ordinary RBD, i.e., arbitrarily pooling experimental and sampling error. There are, of course, pooling tests available in the literature (see, e.g., Bancroft, 1964) that permit the analyst to test to see if error (a) and error (b) can be pooled in the SP design as well to test for pooling of experimental and sampling error in the RBD with sampling.

9. Repeated measures experiments should be analyzed as such. These designs are very common in biology and agriculture; I think that we as biometricians have been negligent in not recognizing their ubiquitousness and importance. Examples are common: a RBD with different forage cultivars, but multiple harvests; multiple "testers" or "judges" in sensory evaluation experiments, each following a balanced ICBD; and a class of graduate students performing a given task, e.g,, spread-sheeting, with three different software packages. In fact, several classes of designs have been developed specifically for the repeated measures situation, e.g., simple two-treatment crossover designs, extensions of crossover design with more than two treatments and/or periods, extra-period Latin square designs, etc. One must be careful in analyzing such sets of data, as the assumption of independence of observations is obviously violated. Certain tests can be made to see if your univariate ANOVAs are robust against the departure exhibited by the given set of data. Gill (1978) gives the analysis of many such experiments.

\section{Literature Cited}

Addelman, S. 1974. Computing the ANOVA table for experiments involving qualitative factors and zero amounts of quantitative factors. Amer. Statistician 28:21-22.

Bancroft, T.A. 1964. Analysis and inference for incompletely specified models involving the use of preliminary test(s) of significance. Biometrics 20:427-444.

Fisher, R.A. 1951. The design of experiments. 6th ed. Oliver and Boyd, London.

Gill, J.L. 1978. Design and analysis of experiments. vol. 1 and 2. Iowa State Univ. Press, Ames.

Hammer, P.A. and N.S. Urquhart. 1979. Precision and replication: Critique II, p. 343-368. In: T.W. Tibbitts and T.T. Kozlowski (eds.). Controlled environment guidelines for plant research. Academic, New York.

Hocking, R.R. 1985. The analysis of linear models. Brooks/Cole, Monterey, Calif.

Hurlbert, S.H. 1984. Pseudoreplication and the design of ecological experiments. Ecological Monographs 54: 187-211.

Jones, D. 1984. Use, misuse and role of multiplecomparison procedures in ecological and agricultural entomology. Environ. Entomol. 13:635649.

Jones, D. and N. Matloff. 1986. Statistical hypothesis testing in biology: a contradiction in terms. J. Econ. Entomol. 79:1156-1160.

Lenter, M. and T. Bishop. 1986. Experimental design and analysis. Valley Book, Blacksburg, Va.

Little, T. 1978. If Galileo published in HortScience. HortScience 13:504-506.

Perry, J.N. 1986. Multiple-comparison procedures: A dissenting view. J. Econ. Entomol. 79:1149-1155.

Sokal, R.R. and F.J. Rohlf. 1981. The principles and practice of statistics in biological research. 2nd ed. W.H. Freeman, San Francisco. 